Article

\title{
Understanding the Partitioning of the Available Energy over the Semi-Arid Areas of the Loess Plateau, China
}

\author{
Guanghui Yuan, Lei Zhang *, Jiening Liang, Xianjie Cao, Hui Liu and Zhaohong Yang
}

Key Laboratory for Semi-Arid Climate Change of the Ministry of Education, College of Atmospheric Sciences, Lanzhou University, Lanzhou 730000, China; yuangh09@lzu.edu.cn (G.Y.); liangjn@lzu.edu.cn (J.L.); caoxj@lzu.edu.cn (X.C.); liuh2012@lzu.edu.cn (H.L.); yangchh09@lzu.edu.cn (Z.Y.)

* Correspondence: zhanglei@lzu.edu.cn

Academic Editor: Andres Schmidt

Received: 16 March 2017; Accepted: 16 May 2017; Published: 22 May 2017

\begin{abstract}
To investigate the mechanism of available energy partitioning to sensible and latent heat fluxes over semi-arid regions, data from the Semi-Arid Climate and Environment Observatory of Lanzhou University (SACOL) were analyzed to assess the effects of soil moisture, net radiation, and vapor pressure deficit (VPD) on available energy partitioning, as quantified by Bowen ratio. It was found that the Bowen ratio decreased rapidly with increasing soil moisture when soil was dry but was insensitive to the change in soil moisture when soil became wet. Net radiation and VPD affected the sensitivity of the Bowen ratio to soil moisture under dry conditions and the soil moisture threshold above which the Bowen ratio became insensitive to soil moisture. The Bowen ratio increases with net radiation at a high level of VPD, while the Bowen ratio first increases and then decreases with net radiation at a low level of VPD. Reduced soil moisture enhanced the effects of the net radiation and VPD on available energy partitioning. The effects of the VPD on Bowen ratio depended on the relative strength of the positive and negative impacts of VPD on the latent heat flux under different soil and net radiation conditions.
\end{abstract}

Keywords: available energy partitioning; soil moisture; net radiation; vapor pressure deficit; semi-arid areas

\section{Introduction}

Mass and energy exchanges between the land surface and atmosphere are key components of land-atmosphere interactions [1-3]. Sensible heat flux and latent heat flux, key variables in energy and water vapor exchanges between the land surface and atmosphere, drive the dynamics of the Earth's major water, energy, and biogeochemical cycles [4,5] and concurrently govern the evolution and characteristics of the planetary boundary layer, such as its depth, thermodynamic behavior, the surface air temperature, and humidity [6,7]. The available energy, which is the difference between the net radiation and soil heat flux, is partitioned into the sensible heat flux and latent heat flux $[8,9]$. This partitioning of available energy has an important effect on regional climates, the water cycle, boundary layer characteristics, and cloud development [10-13]. The key issues concerning energy partitioning are the differences in partitioning across different climates and ecosystems and the mechanisms behind these differences [14].

Numerous studies have investigated energy partitioning. Zeng et al. [15] used a series of Weather Research and Forecasting (WRF) model simulations to investigate the sensitivity of high-temperature weather to soil moisture over the humid region in East China and found that soil moisture affected the high temperature by influencing the partitioning of energy. Zhang et al. [16] conducted two long-term 
simulations using WRF to assess the contribution of land-atmosphere coupling to the interannual variability of summer climate over East Asia, showing that soil moisture-temperature coupling is largely determined by the ability of soil moisture to affect surface fluxes. Cho et al. [17] evaluated the effect of temperature on land surface energy partitioning using measurement data from 25 FLUXNET sites (http:/ fluxnet.ornl.gov/). A negative relationship was found between Bowen ratio (the ratio of the sensible heat flux to the latent heat flux) and temperature, and this relationship was stronger above less vegetated surfaces with low vapor pressure deficit (VPD) and low amounts of received radiation energy. The partitioning of available energy is influenced by the soil moisture, net radiation, VPD, vegetation condition, and temperature. Based on previous studies that primarily focused on the land-atmosphere interactions affecting temperature or precipitation by influencing energy partitioning, little attention has been paid to analyzing the mechanism of available energy partitioning because of the difficulties in this analysis. The factors that influence the energy partitioning are closely related. On the one hand, soil moisture changes the upward shortwave and longwave radiation by influencing the albedo and emissivity, consequently changing the net radiation. There is also a close relationship between the soil moisture and vegetation. Furthermore, numerous studies have found that soil moisture can affect temperature through changes in the sensible and latent heat flux. On the other hand, changing the partitioning of energy can also influence these factors. The combination of an increasing sensible heat flux and decreasing latent heat flux would enhance the temperature, decrease the relative humidity and precipitation, and intensify drought. In summary, all these aspects complicate the relationship between these factors and energy partitioning $[18,19]$. This paper aims to answer the questionof how soil moisture, net radiation, and VPD affect the partitioning of available energy over the semi-arid areas of the Loess Plateau in China.

Arid and semi-arid regions account for approximately one-third of the Earth's surface land area [20]. As the largest arid and semi-arid zone in China, the Loess Plateau is sensitive to climate change [21-23]. Land-atmosphere interactions in this area do not only have a significant impact on the regional climate but also affect the monsoon circulation in China [24]. As of April 2014, FLUXNET had established 683 tower sites to operate on a long-term and continuous basis. These sites are less distributed in arid and semi-arid areas, limiting the research on the land-atmosphere interactions over arid and semi-arid regions.

The Semi-Arid Climate and Environment Observatory of Lanzhou University (SACOL) has filled the gap in long-term and continuous observations over the semi-arid regions of the Loess Plateau in northwest China, providing convenient conditions for studying the mechanism of available energy partitioning over semi-arid regions. Soil moisture impacts are suggested to be larger than oceanic impacts over continental mid-latitudes during warmer seasons [25-28]. With all these considerations in mind, the soil moisture, net radiation, and atmospheric humidity during the summer of 2007-2008 were classified to research the effects of atmospheric and surface conditions on energy partitioning.

\section{Station, Data, and Method of Analysis}

\subsection{Station Description}

SACOL was established in 2005 and is located at $35.946^{\circ} \mathrm{N}, 104.137^{\circ} \mathrm{E}$ at an altitude of $1965.8 \mathrm{~m}$, approximately $48 \mathrm{~km}$ from the center of Lanzhou in the semi-arid regions of China. The topography around the site is characterized by the Loess Plateau, consisting of plains, ridges, and mounds, with elevations ranging between $1714-2089 \mathrm{~m}$. The parent soil material is mainly Quaternary aeolian loess, with the main soil type being sierozem. With international advanced instruments, SACOL, as one of the reference sites of the international Coordinated Energy and Water Cycle Observations Project (CEOP), is the second long-term observation station constructed over a semi-arid area in China, following the Chinese Academy of Sciences' Jilin Tongyu station $\left(44.25^{\circ} \mathrm{N}, 122.52^{\circ} \mathrm{E}\right)$. The flat terrain around the station expands approximately $200 \mathrm{~m}$ from east to west and more than $1000 \mathrm{~m}$ from north to south. The dominant species covering the surface are Stipa bungeana, as well as Artemisia frigida and 
Leymus secalinus. The height of vegetation is about $0.24 \mathrm{~m}$ in summer and $0.10 \mathrm{~m}$ in winter. SACOL has a temperate semi-arid climate with an annual average temperature of $6.7^{\circ} \mathrm{C}$ and an annual rainfall of $381.8 \mathrm{~mm}$, the highest average temperature of approximately $20^{\circ} \mathrm{C}$ occurs in July, and the maximum precipitation of approximately $90 \mathrm{~mm}$ occurs in August. For more information about SACOL, please refer to Huang et al. [29].

\subsection{Data}

To gain an insight into the mechanism of available energy partitioning over the semi-arid regions, we analyzed the eddy covariance (EC) data including the sensible heat flux and latent heat flux, surface radiation, and boundary layer meteorological parameters including air temperature, relative humidity, precipitation, and soil moisture during daytime from 1 June to 31 August during 2007 and 2008.

The fluxes of sensible and latent heat were measured at $3.0 \mathrm{~m}$ using a three-axis sonic anemometer (CSAT3, Campbell, Camden, NJ, USA) that measured $u, v, w$ and the sonic temperature and an open-path infrared $\mathrm{CO}_{2}$ and $\mathrm{H}_{2} \mathrm{O}$ analyzer (LI7500, LI-COR,) that measured the density of water vapor. These signals were logged by a data logger (CR5000, Campbell) at $10 \mathrm{~Hz}$. Necessary corrections and quality controls of the turbulent fluxes, such as eliminating spikes [30], coordinate rotation [31], sonic temperature correction [9,32], Webb_Pearman_Leuning (WPL) density correction (correction for density fluctuations) [33], test of stationary [34] and integral turbulent characteristics [35], were applied to obtain high quality data. For more information about the data processing, please refer to Yuan et al. [36].

The surface radiation was measured at $1.5 \mathrm{~m}$ with upward and downward pyranometers (CM21, Kipp and Zonen, Delftechpark, Netherlands) for outgoing and incoming shortwave radiation and upward and downward pyrgeometers (CG4, Kipp and Zonen) for outgoing and incoming longwave radiation. The VPD was calculated from the air temperature and relative humidity (HMP45C-L, Vaisala, Vantaa, Finland) which were measured at 1, 2, 4, 8, 12, 16, and $32 \mathrm{~m}$. The soil moisture was measured using five water content reflectometers (CS616-L, Campbell) at 0.05, 0.10, 0.20, 0.40 , and $0.80 \mathrm{~m}$ depth and the average of five layers was used to classify dry and wet conditions. Precipitation was measured with a tipping bucket rain gauge (TE525MM-L, Texas Electronics, Dallas, TX, USA) at $0.30 \mathrm{~m}$.

\subsection{Method of Analysis}

The soil moisture, net radiation, and atmospheric humidity data during the summer of 2007-2008 were used to study the effects of atmospheric and surface conditions on energy partitioning. The effect of wind speed on energy partitioning was found to be insignificant at our site (results not shown here). Hence, wind speed was not considered for the analyses presented in this study. The Bowen ratio can be used as an indicator of the available energy partitioning. Notably, the soil moisture, net radiation, and VPD are interactional when analyzing their effects on energy partitioning. Soil moisture influences the net radiation through the effects on surface albedo, emissivity, and water vapor evaporation in the air. The surface albedo decreases with increasing soil moisture, thereby weakening the upward shortwave radiation. At the same time, the increasing soil moisture could increase the emissivity, further enhancing the upward longwave radiation. Moreover, the evaporation of water vapor in the air induced by increasing soil moisture exerts greenhouse effects and strengthens the downward longwave radiation. Soil moisture and VPD are correlated such that very high (low) VPD may not occur when soil is wet (dry) [37]. Therefore, the soil moisture, net radiation, and VPD are divided into two, four, and four levels, respectively, thus ensuring that the effects of the other two factors can be neglected when discussing the effects of one factor on the energy partitioning. Considering the differences after classification and the amount of data, the net radiation is divided into four levels, $<150,150-300,300-500$, and $>500 \mathrm{~W} \mathrm{~m}^{-2}$ and the VPD is divided into four levels, $<6,6-12,12-20$, and $>20 \mathrm{hPa}$. 
Mohan and Rao [38] and Sandeep et al. [39] described a methodology to identify wet and dry episodes using rainfall data. The present study uses a similar classification method but for soil moisture. The period is considered as wet (dry) if the soil moisture is higher (lower) than the soil moisture threshold (defined as the average of six years 2007-2012) on the same calendar day for at least three continuous days. Additionally, one or two days in an extended wet (dry) episode are considered as wet (dry) even if the soil moisture on those days is less (more) than the threshold. Figure 1 depicts the procedure for identifying wet/dry days during the summer of 2007-2008. Precipitation influences the accuracy of latent heat flux data, therefore, days with rainfall (green bars in Figure 1) are excluded.

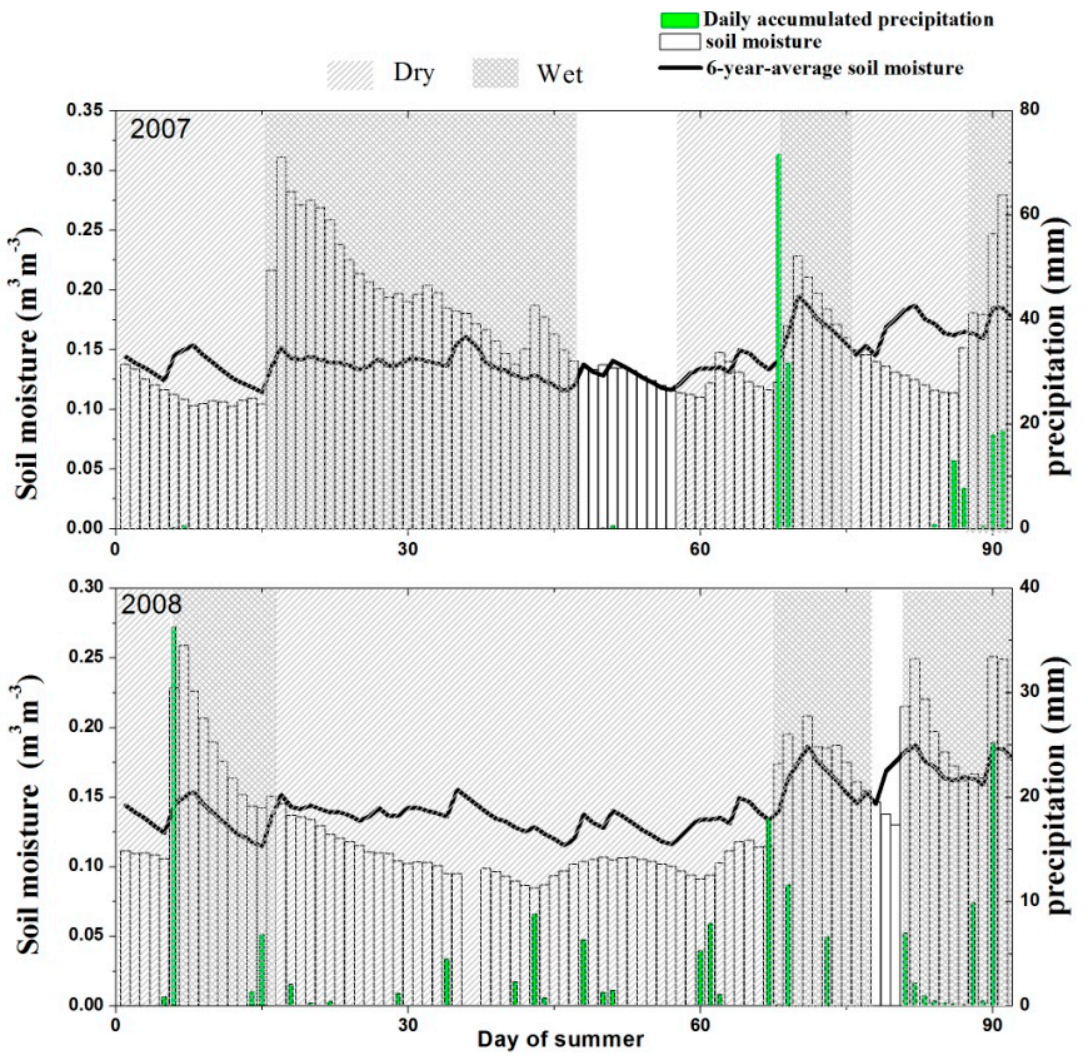

Figure 1. Six-year-average (2007-2012) soil moisture (black line) and the daily average of soil moistureduring the summer of 2007-2008 (hollow bars), and daily accumulated precipitation during the summer of 2007-2008 (green bars).

\section{Results}

\subsection{Effects of Soil Moisture on Energy Partitioning}

Figure 2 shows the impact of soil moisture on the Bowen ratio under different net radiation and VPD conditions. The Bowen ratio decreases rapidly with increasing soil moisture when the soil is lower than a threshold under relatively dry conditions (the threshold will be analyzed further below). However, as soil moisture increases to more than the threshold, the Bowen ratio becomes insensitive to the soil moisture, which is similar to the results of $\mathrm{Gu}$ et al. [18] for a temperate forest site affected by a prolonged drought. The main reason for this phenomenon is that soil moisture does not limit evapotranspiration and vegetation stomatal conductance under conditions of adequate soil water content. Therefore, evapotranspiration and stomatal conductance are controlled by atmospheric conditions such as the net radiation and VPD but not the available water content in soil, which results in the Bowen ratio being insensitive to the changes in soil moisture. When the soil becomes dry, evapotranspiration and stomatal conductance are mainly controlled by soil moisture and become 
sensitive to even small changes in the soil moisture values. VPD and net radiation could affect the change in Bowen ratio with soil moisture. Increasing the VPD and net radiation enhances the sensitivity of the Bowen ratio to soil moisture when soil moisture is lower than the threshold under dry conditions. The soil moisture threshold above which the Bowen ratio shifts from being sensitive to being insensitive to the change in soil moisture increases with increasing VPD and net radiation. For example, the threshold is about $0.10 \mathrm{~m}^{3} \mathrm{~m}^{-3}$ when VPD is $0-6 \mathrm{hPa}$ and net radiation is $0-150 \mathrm{~W}$ $\mathrm{m}^{-2}$, while the threshold is about $0.175 \mathrm{~m}^{3} \mathrm{~m}^{-3}$ when VPD is greater than $20 \mathrm{hPa}$ and net radiation is more than $500 \mathrm{~W} \mathrm{~m}^{-2}$. Moreover, increasing net radiation could also enhance the stable value of Bowen ratio, when the Bowen ratio is insensitive to soil moisture.
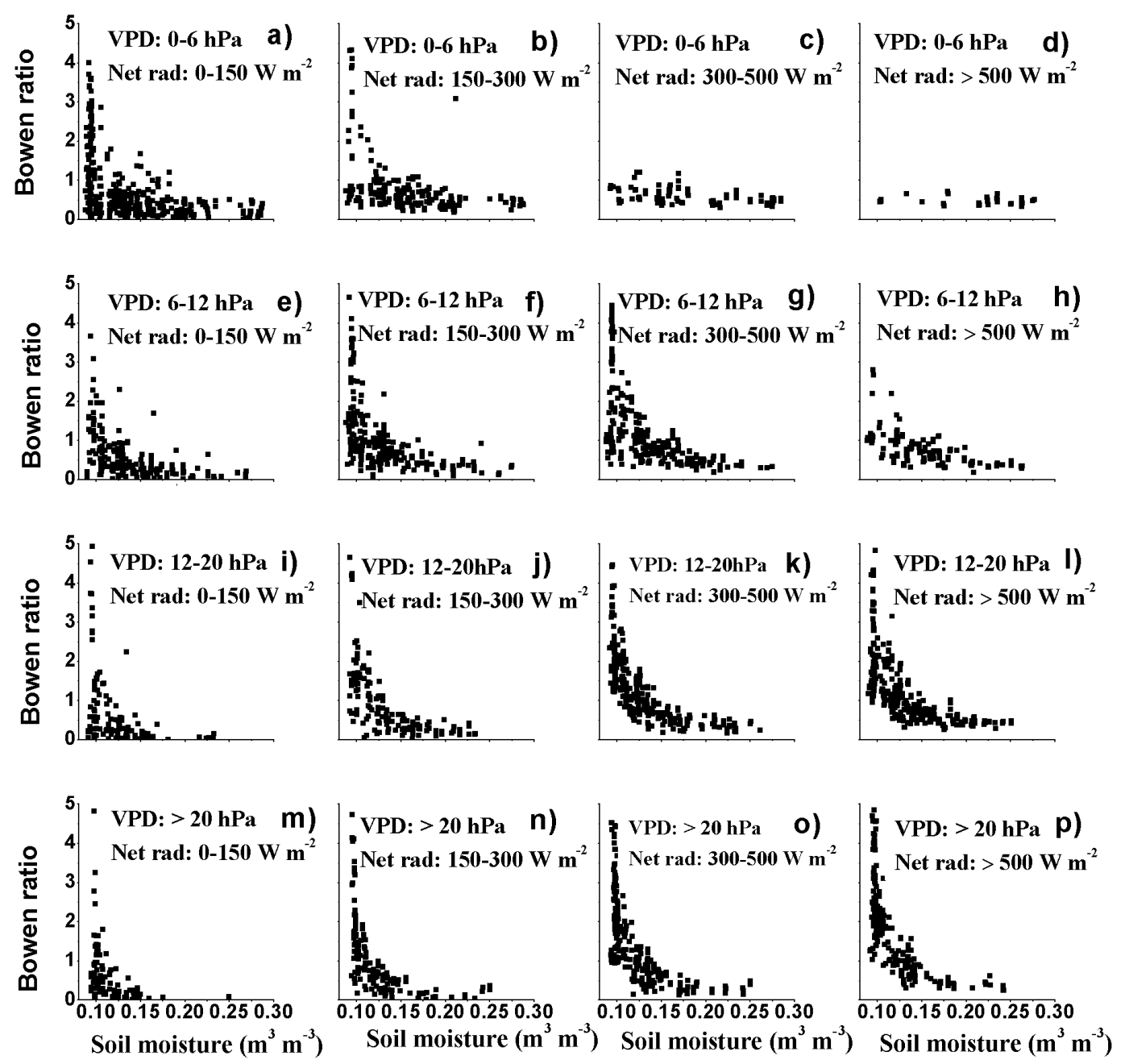

Figure 2. Effects of soil moisture on energy partitioning at different levels of vapor pressure deficit(VPD) ((a-d) 0-6 hPa, (e-h) 6-12 hPa, (i-1) 12-20 hPa and (m-p) $>20 \mathrm{hPa})$ and net radiation $((\mathbf{a}, \mathbf{e}, \mathbf{i}, \mathbf{m})$ 0-150 W $\mathrm{m}^{-2},(\mathbf{b}, \mathbf{f}, \mathbf{j}, \mathbf{n}) 150-300 \mathrm{~W} \mathrm{~m}^{-2},(\mathbf{c}, \mathbf{g}, \mathbf{k}, \mathbf{o}) 300-500 \mathrm{~W} \mathrm{~m}^{-2}$, and $\left.(\mathbf{d}, \mathbf{h}, \mathbf{l}, \mathbf{p})>500 \mathrm{~W} \mathrm{~m}^{-2}\right)$.

\subsection{Effects of Net Radiation on Energy Partitioning}

The Bowen ratio first increases and then decreases with the net radiation at a low level of VPD $(\mathrm{VPD}<12 \mathrm{hPa}$ ), especially under dry conditions (Figure 3a,b). However, at a high level of VPD $(>12 \mathrm{hPa})$, the Bowen ratio increases with net radiation (Figure $3 \mathrm{c}, \mathrm{d})$. The differences of changes in Bowen ratio with net radiation between high and low level of VPD will be discussed below. The Bowen ratio under dry conditions is larger than under wet conditions, indicating more available energy is partitioned to sensible heat flux under dry conditions. 

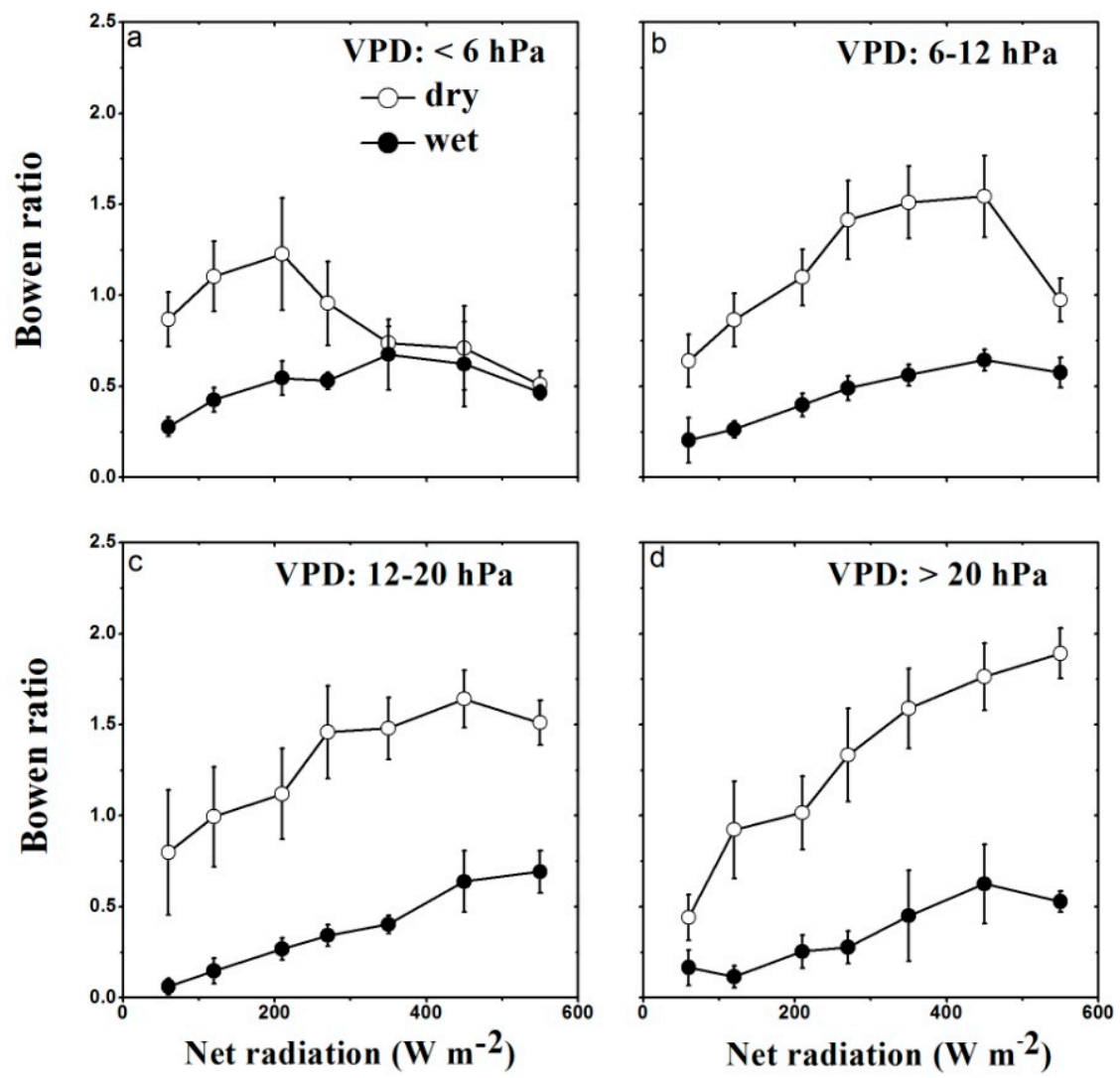

Figure 3. Effects of net radiation on energy partitioning under dry and wet conditions at different VPD levels ((a) $<6 \mathrm{hPa}$, (b) 6-12 hPa, (c) 12-20 hPa, (d) $>20 \mathrm{hPa}$ ). Error bars represent the $95 \%$ confidence intervals.

The effects of VPD on the relationship between Bowen ratio and net radiation can be clearly seen in Figure 4a,b. The Bowen ratio decreases with increasing VPD at low levels of net radiation and increases with an increasing VPD at high levels of net radiation. Wet conditions mainly correspond to the former situation when the values of net radiation are less than $500 \mathrm{~W} \mathrm{~m}^{-2}$, and dry conditions mainly correspond to the latter situation when the values of net radiation are more than $225 \mathrm{~W} \mathrm{~m}^{-2}$. The sensitivity of Bowen ratio to VPD is enhanced with increasing net radiation under dry conditions. To understand the changes in Bowen ratio with net radiation, the impact of net radiation on latent and sensible heat flux are analyzed in Figure 4c-f. The latent heat flux changes more under wet conditions than dry conditions, whereas the trend of the sensible heat flux is the opposite, resulting in less changes in Bowen ratio with net radiation under wet than dry conditions. This result indicates that the decrease in soil moisture enhances the effect of net radiation on the Bowen ratio. In the case of wet soil, latent heat flux increasing with the VPD shifts to decreasing with the VPD, whereas the trend of sensible heat flux is the opposite, resulting in a decreasing Bowen ratio with increased VPD shifting to an increasing Bowen ratio with increased VPD. The Bowen ratio first increasing and then decreasing with the net radiation at a low level of VPD $(<12 \mathrm{hPa})$, especially under dry conditions, is caused by the speed of the increase in latent heat flux being larger than sensible heat flux at high levels of net radiation. The effect of VPD on latent heat flux will be discussed in Section 3.3. Bowen ratio, and latent and sensible heat fluxes have the highest sensitivity to VPD at high levels of net radiation under dry conditions but low sensitivity to VPD under wet conditions or at low levels of net radiation under dry conditions. Decreased soil moisture enhances the effect of VPD on the relationship between Bowen ratio and net radiation at a high level of net radiation. 

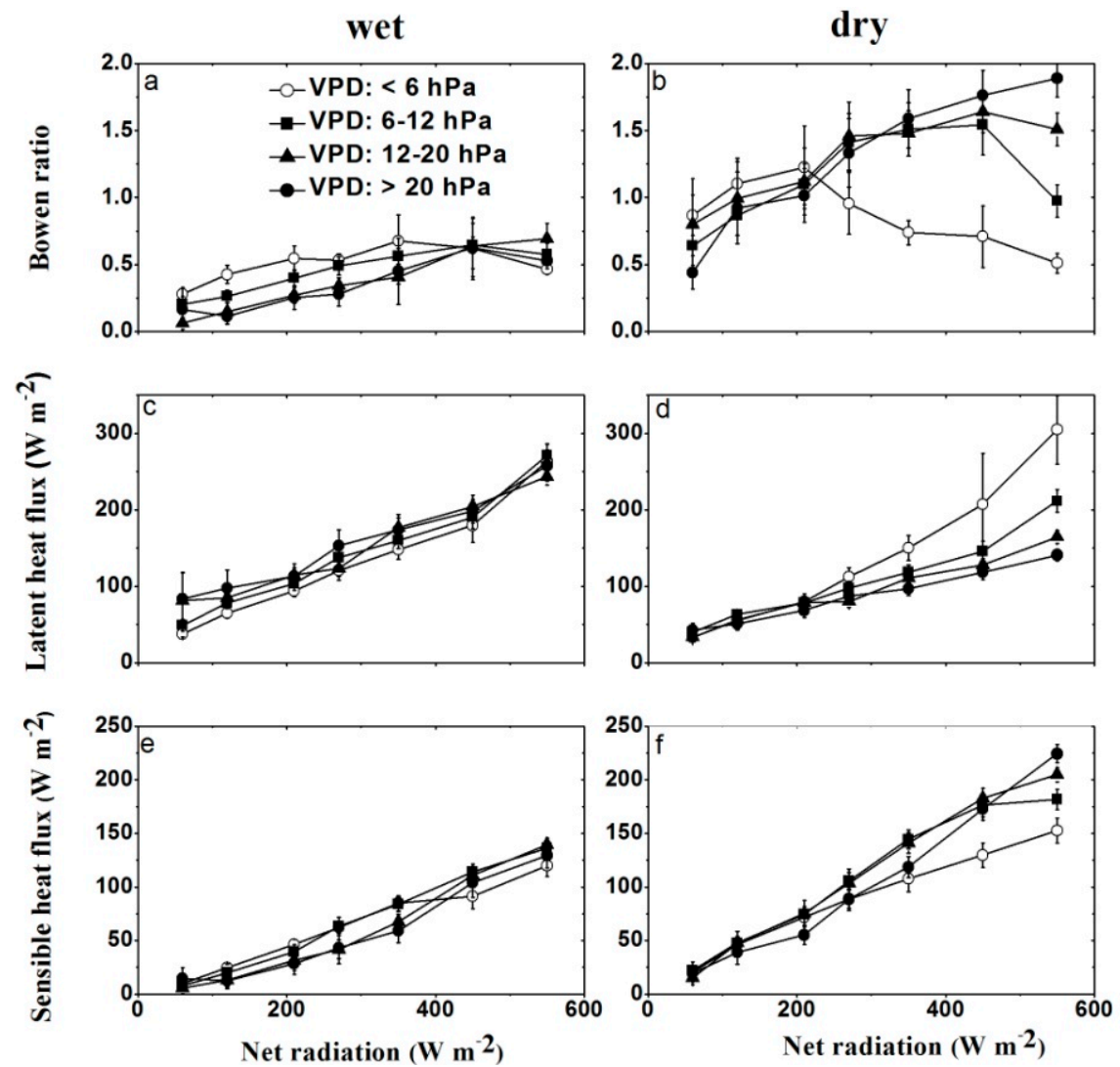

Figure 4. Effects of net radiation on $(\mathbf{a}, \mathbf{b})$ energy partitioning and the $(\mathbf{c}, \mathbf{d})$ latent heat flux and $(\mathbf{e}, \mathbf{f})$ sensible heat flux under drought and wet conditions at different VPD levels. Error bars represent the $95 \%$ confidence intervals.

\subsection{Effects of VPD on Energy Partitioning}

The distribution values of VPD under wet conditions are lower than that under dry conditions (Figure 5). When soil water content is high, the values of Bowen ratio are mostly less than 1.5 and change little with VPD. Bowen ratio exhibits the opposite trends with VPD depending on the level of net radiation under wet conditions (Figure $5 \mathrm{a}, \mathrm{c}, \mathrm{e}, \mathrm{g}$ ). At a low level of net radiation, the Bowen ratio decreases with an increasing VPD (Figure 5a,c,e); conversely, the Bowen ratio increases with an increasing VPD when the net radiation is enhanced (Figure $5 \mathrm{~g}$ ). The values of Bowen ratio are dispersed, ranging up to 5 under dry conditions, illustrating that the Bowen ratio becomes sensitive to VPD when soil moisture decreases (Figure $5 b, d, f, h$ ). Similarly, the Bowen ratio decreases with an increasing VPD at low levels of net radiation (Figure $5 b, d$ ), but not as obviously as under wet conditions. At a high level of net radiation under dry conditions, the Bowen ratio increases with an increasing VPD (Figure 5f,h). In other words, the level of net radiation and soil water content affect the relationship between VPD and Bowen ratio. The decreasing soil moisture and increasing net radiation change the impact of VPD on Bowen ratio from negative to positive.

Under wet conditions, the latent heat flux increases with VPD at low levels of VPD but becomes constant or even declines with an increasing VPD at high levels of net radiation (Figure 6a). The sensible heat flux is insensitive to the VPD under wet conditions (Figure 6b), resulting in the Bowen ratio decreasing with increasing VPD shifting to the Bowen ratio increasing with increasing VPD as the net radiation increases. Under dry conditions, the latent heat flux decreases with an increasing VPD at high levels of net radiation, while sensible heat flux behaves contrarily (Figure $6 c, d)$. Moreover, latent heat flux and sensible heat flux both change little with VPD at low levels of net radiation, indicating that high levels of net radiation correspond to large magnitudes of changes in the heat fluxes. Therefore, 
as shown in Figure 5h, the highest level of net radiation corresponds to the sharpest increase in the Bowen ratio with VPD.
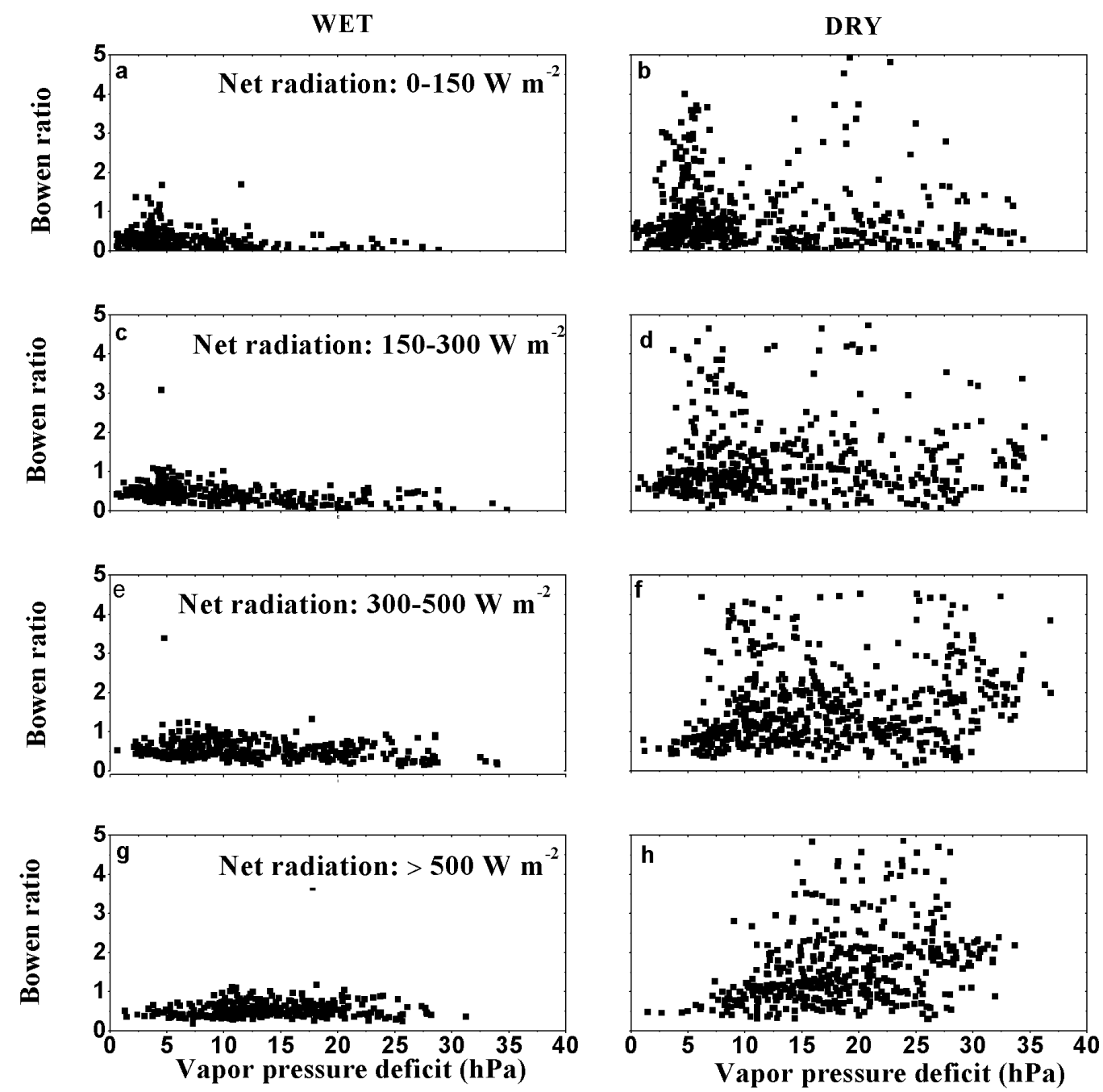

Figure 5. Effects of the VPD on energy partitioning under drought and wet conditions at different net radiation levels $\left((\mathbf{a}, \mathbf{b}) 0-150 \mathrm{~W} \mathrm{~m}^{-2}\right.$, (c,d) $150-300 \mathrm{~W} \mathrm{~m}^{-2},(\mathbf{e}, \mathbf{f}) 300-500 \mathrm{~W} \mathrm{~m}^{-2}$, and $\left.(\mathbf{g}, \mathbf{h})>500 \mathrm{~W} \mathrm{~m}^{-2}\right)$.

The changes in the relationship between VPD and Bowen ratio from negative to positive are mainly caused by two inconsistent influences of the VPD on latent heat flux. On the one hand, the VPD enables the stomata of vegetation or the soil to release more water vapor. Therefore, higher VPD corresponds to larger latent heat flux, as a positive impact. On the other hand, the VPD will affect the stomatal conductance of vegetation such that a higher VPD can reduce the stomatal conductance and water vapor released from vegetation, resulting in less latent heat flux, as a negative impact [40]. As shown in Figure 6a, even under relatively wet conditions in the semi-arid region, the positive effect of VPD initially dominates. With further increases in the VPD, stomatal conductance is reduced, the negative impact diminishes the positive impact, and the latent heat flux becomes invariant or even decreases with an increasing VPD because the available water in vegetation and soil is limited. Under dry conditions, the negative impact dominates to decrease the latent heat flux as VPD increases. At a low level of net radiation, the assigned latent heat flux is low and therefore shows no obvious negative impacts generated by VPD. 

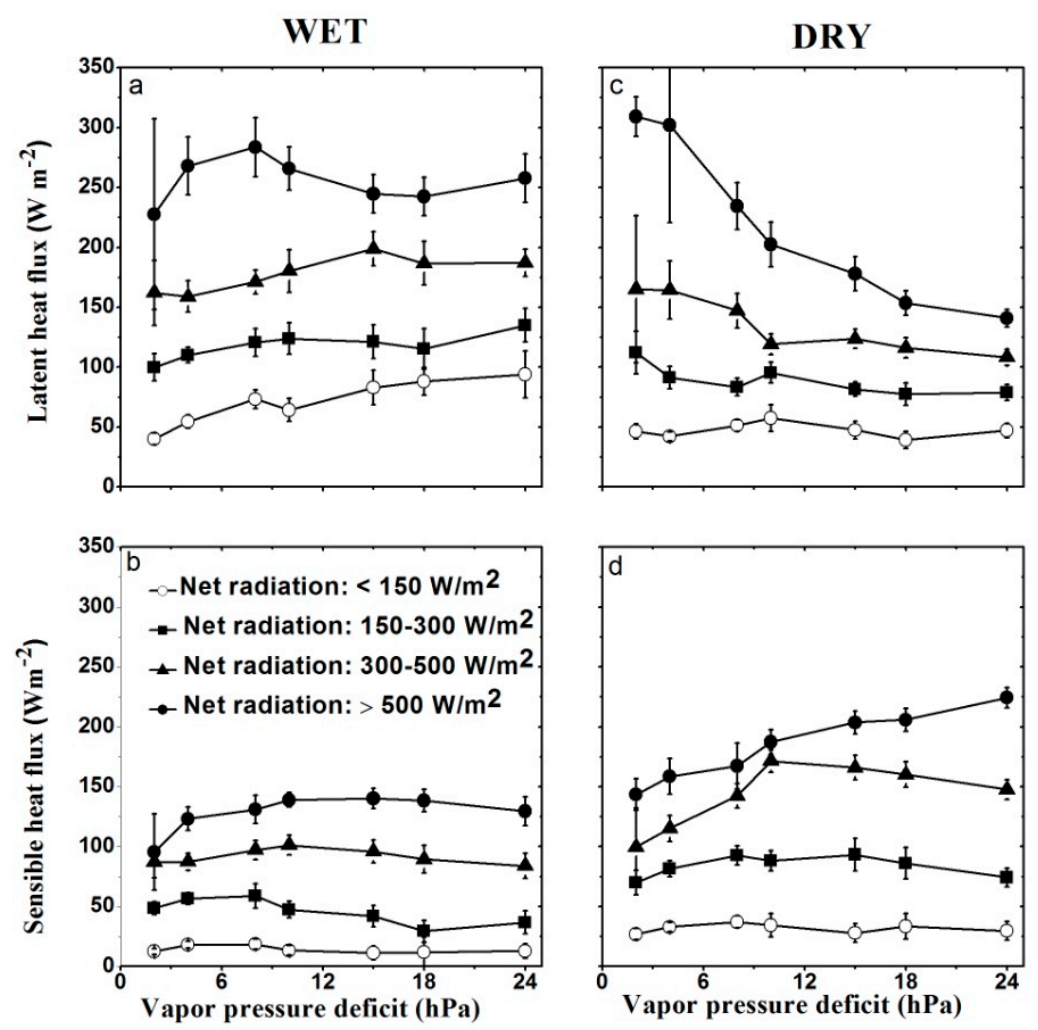

Figure 6. Effects of the VPD on the (a,b) latent heat flux and $(\mathbf{c}, \mathbf{d})$ sensible heat flux under drought and wet conditions at different net radiation levels. Error bars represent the $95 \%$ confidence intervals.

\section{Discussion}

\subsection{Direct and Indirect Effects of Soil Moisture}

The Bowen ratio decreases rapidly with increasing soil moisture under relatively dry conditions, and becomes insensitive to the change in soil moisture as soil becomes wet. The soil moisture values at which this sensitivity changes range from $0.10 \mathrm{~m}^{3} \mathrm{~m}^{-3}$ to $0.175 \mathrm{~m}^{3} \mathrm{~m}^{-3}$ as influenced by the condition of net radiation and VPD.

Decreasing soil moisture increases the Bowen ratio and enhances the magnitude of the changes in Bowen ratio with net radiation and increases the sensitivity of the relationship between Bowen ratio and net radiation to the VPD at high levels of net radiation (Figures 3 and $4 a, b)$. Negative effects of VPD on latent heat flux dominate under dry conditions at high levels of net radiation resulting in an increasing Bowen ratio with VPD (Figure 4). Decreased soil moisture enhances the impact of the net radiation and VPD on available energy partitioning.

The soil moisture influences the positive and negative effects of VPD on latent heat flux. Under dry conditions, the limited soil water content constrains the stomatal conductance of vegetation, resulting in the dominance of the negative effect of VPD on latent heat flux. Under wet conditions, the VPD contributes to vegetation and soil releasing more water vapor and increasing latent heat flux, which results in the positive effect dominating (Figure 6a,b). In addition, reduced soil moisture enhances the sensitivity of Bowen ratio to VPD, further illustrating that decreased soil moisture could enhance the effect of VPD on energy partitioning. The Bowen ratio shifts from decreasing with increased VPD at a low level of net radiation under wet conditions to increasing with increased VPD at a high level of net radiation under dry conditions (Figure 5). 


\subsection{Direct and Indirect Effects of Net Radiation}

The Bowen ratio increases with net radiation at a high level of VPD $(>12 \mathrm{hPa})$, while the Bowen ratio first increases and then decreases with net radiation at a low level of VPD ( $<12 \mathrm{hPa}$, Figure 3$)$. An increasing VPD will inhibit the increase of latent heat flux with net radiation under dry conditions, whereas the effects of VPD on stomatal conductance are negligible when the VPD is low (Figure 4d). Therefore, at a low level of VPD, the speed of the increase in latent heat flux with net radiation is faster than that of the increase in sensible heat flux when there is high enough net radiation (net radiation $>225 \mathrm{~W} \mathrm{~m}^{2}$, Figure $\left.4 \mathrm{~d}, \mathrm{f}\right)$. Consequently, the trend of the Bowen ratio increasing with net radiation turns to decreases with net radiation at a low level of VPD under dry conditions (Figure 4b).

The effects of net radiation on the relationship between soil moisture and Bowen ratio are mainly reflected in the following aspects. Increasing net radiation increases the soil moisture threshold above which point the Bowen ratio shifts from being sensitive to insensitive to changes in soil moisture and tends to enhance the stable value of the Bowen ratio at which the ratio is insensitive to soil moisture changes under relatively wet conditions. In addition, increasing net radiation enhances the sensitivity of the Bowen ratio to soil moisture changes under dry conditions (Figure 2).

The positive effect of VPD on latent heat flux dominates at low levels of net radiation, resulting in a decreasing Bowen ratio with an increasing VPD, whereas the negative effect dominates, resulting in a shift of a decreasing Bowen ratio with VPD turning to an increasing Bowen ratio with the VPD, at high levels of net radiation. The strongest sensitivity of the relationship between VPD and latent heat flux to net radiation appears at low levels of VPD under dry conditions (Figure 6b). The effects of VPD on stomatal conductance are negligible when VPD is at a low level under dry conditions, therefore, the main differences between latent heat flux are generated by net radiation. The restriction on stomatal conductance could be enhanced by increasing the VPD. Increased net radiation amplifies the negative impact of VPD on latent heat flux, whereas the VPD has little effect on latent heat flux when the net radiation is at a low level. Therefore, the sensitivity of the relationship between latent heat flux and VPD to net radiation decreases with an increasing VPD under dry conditions.

\subsection{Direct and Indirect Effects of VPD}

The effects of VPD on Bowen ratio depend on the role of the positive and negative effects of VPD on latent heat flux. The positive and negative impacts mainly rely on the soil moisture conditions and the level of net radiation.

The impact of VPD on the relationship between the soil moisture and Bowen ratio is similar to the impact of net radiation. An increasing VPD increases the soil moisture threshold above which point the Bowen ratio shifts from sensitive to insensitive to the changes in soil moisture and tends to enhance the sensitivity of Bowen ratio to soil moisture under dry conditions (Figure 2).

The VPD exerts positive effects on latent heat flux at low levels of net radiation but negative effects on latent heat flux when the net radiation increases. Positive effects dominate under wet conditions and negative effects dominate under dry conditions. The strongest sensitivity of the relationship between net radiation and Bowen ratio to VPD appears at a high level of net radiation under dry conditions. This is mainly due to the negative effects of VPD on latent heat flux dominating under dry conditions, and the effects of VPD on stomatal conductance are negligible when the VPD is low. At low levels of net radiation, the assigned latent heat flux itself is small, producing little differences due to the VPD. While the differences among the latent heat fluxes are enhanced by an increased latent heat flux resulting from greater net radiation, the negative effects are also enhanced by an increasing VPD, resulting in a lower latent heat flux than that at a low level of VPD. Consequently, the sensitivity is strongest at high levels of net radiation under dry conditions. 


\section{Conclusions}

We analyzed data from SACOL for the summers of 2007-2008 to investigate the mechanism of available energy partitioning over the semi-arid region.

The Bowen ratio decreases rapidly with increasing soil moisture under relatively dry conditions, while the Bowen ratio becomes insensitive to soil moisture changes as the soil becomes wet; the net radiation may be the primary factor to affect the energy partitioning. Therefore, bigger Bowen ratios appear under dry conditions and smaller Bowen ratios appear under wet conditions. Increasing VPD and net radiation on one hand increase the soil moisture threshold above which point the Bowen ratio shifts from being sensitive to insensitive to changes in soil moisture. On the other hand, the sensitivity of the Bowen ratio to soil moisture is enhanced under dry soil conditions. Moreover, increasing net radiation enhances the stable value of the Bowen ratio at which point the ratio is insensitive to soil moisture changes under relatively wet conditions.

The Bowen ratio increases with net radiation at a high level of VPD $(>12 \mathrm{hPa})$, while the Bowen ratio first increases and then decreases with net radiation at a low level of VPD $(<12 \mathrm{hPa})$. Decreased soil moisture enhances the impact of net radiation on available energy partitioning and the sensitivity of the relationship between the Bowen ratio and net radiation to VPD at high levels of net radiation. The biggest Bowen ratio appears at the highest levels of net radiation $\left(>500 \mathrm{~W} \mathrm{~m}^{-2}\right)$ and VPD $(>20 \mathrm{hPa})$ under dry conditions.

The effects of VPD on the Bowen ratio depend on the role of positive and negative effects of VPD on latent heat flux. Reduced soil moisture enhances the sensitivity of the Bowen ratio to VPD. Net radiation and soil moisture have combined effects on the relationship between VPD and the Bowen ratio. The positive effects dominate at low levels of net radiation under wet conditions, resulting in a decreasing Bowen ratio with an increasing VPD. Negative effects dominate at high levels of net radiation under dry conditions, resulting in a shift in the Bowen ratio to increase with an increasing VPD.

The results have important implication for understanding some land atmosphere processes. Zhang et al. [41] calculated the soil moisture feedback parameters to study the effects of soil moisture on diurnal temperature ranges across the contiguous United States. Both the negative and positive effects of soil moisture on diurnal temperature range were reflected in the study area. The differences of the effects may result from the direct and indirect effects of soil moisture and atmospheric conditions on energy partitioning.

Wilson et al. [14] investigated the climatic control (quantified using the climatological resistance, which was proportional to the ratio of VPD to net radiation) on Bowen ratio using 27 FLUXNET sites and suggested that large values of climatological resistance decreased the Bowen ratio. Odongo et al. [40] had similar results in the semi-arid ecosystem which suggested that during the dry seasons, drought conditions in combination with highs level of VPD lead to significant decreases in stomatal conductance that eventually limit partitioning of available energy into latent heat flux. However, during the wet season these factors are non-limiting and radiation is the dominant control of energy partitioning. Gu et al. [18] conducted a similar research study during a prolonged drought at a temperate forest site. The differences in our findings from the results of $\mathrm{Gu}$ et al. may result from the very different vegetation structures. The findings in this research are based on observational data from SACOL and are considered representative for the Loess Plateau. In order to confirm that our findings are transferrable to other semi-arid regions, more observational data from different sites and further analyses in future related research studies are needed.

Acknowledgments: The authors would like to thank the Semi-Arid Climate and Environment Observatory of Lanzhou University (SACOL) for providing the observational data. This research was supported by the National Natural Science Foundation of China (41475008, 41521004, 41605005).

Author Contributions: Lei Zhang provided the initial idea of this paper. Guanghui Yuan processed and analyzed the data and wrote the paper under the guidance of Lei Zhang. Jiening Liang, Xianjie Cao, Hui Liu, and Zhaohong Yang provided the observation data and offered useful suggestions for data processing. 
Conflicts of Interest: The authors declare no conflict of interest.

\section{References}

1. Dickinson, R.E. Land surface processes and climate-surface albedos and energy balance. Adv. Geophys. 1983, 25, 305-353. [CrossRef]

2. Avissar, R. Recent advances in the representation of land-atmosphere interactions in general circulation models. Rev. Geophys. 1995, 33, 1005-1010. [CrossRef]

3. Yang, R.; Friedl, M.A. Modeling the effects of three-dimensional vegetation structure on surface radiation and energy balance in boreal forests. J. Geophys. Res. Atmos. 2003, 108, 8615-8625. [CrossRef]

4. Gentine, P.; Entekhabi, D.; Heusinkveld, B. Systematic errors in ground heat flux estimation and their correction. Water Resour. Res. 2012, 48, W09541. [CrossRef]

5. Xu, T.; Bateni, S.M.; Liang, S.; Entekhabi, D.; Mao, K. Estimation of surface turbulent heat fluxes via variational assimilation of sequences of land surface temperatures from Geostationary Operational Environmental Satellites. J. Geophys. Res. Atmos. 2014, 119, 780-798. [CrossRef]

6. Schmid, H.P.; Cleugh, H.A.; Grimmond, C.S.B.; Oke, T.R. Spatial variability of energy fluxes in suburban terrain. Bound. Layer Meteorol. 1991, 54, 249-276. [CrossRef]

7. Beringer, J.; Tapper, N. Surface energy exchanges and interactions with thunderstorms during the Maritime Continent Thunderstorm Experiment (MCTEX). J. Geophys. Res. 2002, 107, 4552-4564. [CrossRef]

8. Wilson, K.; Goldstein, A.; Falge, E.; Aubinet, M.; Baldocchi, D.; Berbigier, P.; Bernhofer, C.; Ceulemans, R.; Dolman, H.; Field, C.; et al. Energy balance closure at FLUXNET sites. Agric. For. Meteorol. 2002, 113, $223-234$. [CrossRef]

9. Aubinet, M.; Vesala, T.; Papale, D. Eddy Covariance: A Practical Guide to Measurement and Data Analysis; Springer Science and Business Media: New York, NY, USA, 2012.

10. Eugster, W.; Rouse, W.R.; Pielke, R.A., Sr.; Mcfadden, J.P.; Baldocchi, D.D.; Kittel, T.G.F.; Chapin, F.S.; Liston, G.E.; Vidale, P.L.; Vaganov, E.; et al. Land-atmosphere energy exchange in Arctic tundra and boreal forest: Available data and feedbacks to climate. Glob. Chang. Biol. 2000, 6, 84-115. [CrossRef]

11. Rouse, W.R. The energy and water balance of high-latitude wetlands: Controls and extrapolation. Glob. Chang. Biol. 2000, 6, 59-68. [CrossRef]

12. Pielke, R.A., Sr. Influence of the spatial distribution of vegetation and soils on the prediction of cumulus Convective rainfall. Rev. Geophys. 2001, 39, 151-177. [CrossRef]

13. Peichl, M.; Sagerfors, J.; Lindroth, A.; Buffam, I.; Grelle, A.; Klemedtsson, L.; Laudon, H.; Nilsson, M.B. Energy exchange and water budget partitioning in a boreal minerogenic mire. J. Geophys. Res. Biogeosci. 2013, 118, 1-13. [CrossRef]

14. Wilson, K.B.; Baldocchi, D.D.; Aubinet, M.; Berbigier, P.; Bernhofer, C.; Dolman, H.; Falge, E.; Field, C.; Goldstein, A.; Granier, A.; et al. Energy partitioning between latent and sensible heat flux during the warm season at FLUXNET sites. Water Resour. Res. 2002, 38, 1294-1304. [CrossRef]

15. Zeng, X.M.; Wang, B.; Zhang, Y.; Song, S.; Huang, X.; Zheng, Y.; Chen, C.; Wang, G. Sensitivity of high-temperature weather to initial soil moisture: A case study using the WRF model. Atmos. Chem. Phys. 2014, 14, 9623-9639. [CrossRef]

16. Zhang, J.; Wu, L.; Dong, W. Land-atmosphere coupling and summer climate variability over East Asia. J. Geophys. Res. 2011, 116, 117-130. [CrossRef]

17. Cho, J.; Oki, T.; Yeh, P.J.F.; Kim, W.; Kanae, S.; Otsuki, K. On the relationship between the Bowen ratio and the near-surface air temperature. Theor. Appl. Climatol. 2011, 108, 135-145. [CrossRef]

18. Gu, L.; Meyers, T.; Pallardy, S.G.; Hanson, P.J.; Yang, B.; Heuer, M.; Hosman, K.P.; Riggs, J.S.; Sluss, D.; Wullschleger, S.D. Direct and indirect effects of atmospheric conditions and soil moisture on surface energy partitioning revealed by a prolonged drought at a temperate forest site. J. Geophys. Res. 2006, 111, 102-114. [CrossRef]

19. Liu, D.; Wang, G.; Mei, R.; Yu, Z.; Yu, M. Impact of initial soil moisture anomalies on climate mean and extremes over Asia. J. Geophys. Res. Atmos. 2014, 119, 529-545. [CrossRef]

20. Huang, J.; Minnis, P.; Yan, H.; Yi, Y.; Chen, B.; Zhang, L.; Ayers, J.K. Dust aerosol effect on semi-arid climate over Northwest China detected from A-Train satellite measurements. Atmos. Chem. Phys. 2010, 10, 6863-6872. [CrossRef] 
21. Fu, Q.; Johanson, C.M.; Wallace, J.M.; Reichler, T. Enhanced mid-latitude tropospheric warming in satellite measurements. Science 2006, 312, 1179. [CrossRef] [PubMed]

22. Ma, Z.; Fu, C. Some evidences of drying trend over North China from 1951 to 2004. Chin. Sci. Bull. 2006, 51, 2913-2925. (in Chinese). [CrossRef]

23. Liang, J.; Zhang, L.; Wang, Y.; Cao, X.; Zhang, Q.; Wang, H.; Zhang, B. Turbulence regimes and the validity of similarity theory in the stable boundary layer over complex terrain of the Loess Plateau, China. J. Geophys. Res. Atmos. 2014, 119, 6009-6021. [CrossRef]

24. Wang, G.; Huang, J.; Guo, W.; Zuo, J.; Wang, J.; Bi, J.; Huang, Z.; Shi, J. Observation analysis of land-atmosphere interactions over the Loess Plateau of northwest China. J. Geophys. Res. 2010, 115, D00K17. [CrossRef]

25. Koster, R.D.; Suarez, M.J. Relative contributions of land and ocean processes to precipitation variability. J. Geophys. Res. 1995, 100, 13775-13790. [CrossRef]

26. Koster, R.D.; Suarez, M.J.; Heiser, M. Variance and predictability of precipitation at seasonal-to-interannual timescales. J. Hydrometeorol. 2000, 1, 26-46. [CrossRef]

27. Douville, H. Relevance of soil moisture for seasonal atmospheric predictions: Is it an initial value problem? Clim. Dyn. 2004, 22, 429-446. [CrossRef]

28. Conil, S.; Douville, H.; Tyteca, S. The relative influence of soil moisture and SST in climate predictability explored within ensembles of AMIP type experiments. Clim. Dyn. 2007, 28, 125-145. [CrossRef]

29. Huang, J.; Zhang, W.; Zuo, J.; Bi, J.; Shi, J.; Wang, X.; Chang, Z.; Huang, Z.; Yang, S.; Zhang, B.; et al. An overview of the Semi-arid Climate and Environment Research Observatory over the Loess Plateau. Adv. Atmos. Sci. 2008, 25, 906-921. [CrossRef]

30. Vickers, D.; Mahrt, L. Quality control and flux sampling problems for tower and aircraft data. J. Atmos. Ocean. Technol. 1997, 14, 512-526. [CrossRef]

31. Wilczak, J.M.; Oncley, S.P.; Stage, S.A. Sonic anemometer tilt correction algorithms. Bound. Layer Meteorol. 2001, 99, 127-150. [CrossRef]

32. Schotanus, P.; Nieuwstadt, F.T.M.; Bruin, H.A.R. Temperature measurement with a sonic anemometer and its application to heat and moisture fluxes. Bound. Layer Meteorol. 1983, 26, 81-93. [CrossRef]

33. Webb, E.K.; Pearman, G.I.; Leuning, R. Correction of flux measurements for density effects due to heat and water vapour transfer. Quart. J. R. Meteor. Soc. 1980, 106, 85-100. [CrossRef]

34. Foken, T.; Wichura, B. Tools for quality assessment of surface-based flux measurements. Agric. For. Meteorol. 1996, 78, 83-105. [CrossRef]

35. Foken, T. The energy balance closure problem: An overview. Ecol. Appl. 2008, 18, 1351-1367. [CrossRef] [PubMed]

36. Yuan, G.; Zhang, L.; Li, Y.; Liang, J. Method of acquiring high-quality surface turbulent fluxes over the Loess Plateau. Chin. J. Geophys. 2016, 59, 382-394.

37. Gu, L.; Fuentes, J.D.; Shugart, H.H.; Staebler, R.M.; Black, T.A. Responses of net ecosystem exchanges of carbon dioxide to changes in cloudiness: Results from two North American deciduous forests. J. Geophys. Res. 1999, 104, 421-434. [CrossRef]

38. Mohan, T.S.; Rao, T.N. Variability of the thermal structure of the atmosphere during wet and dry spells over southeast India. Q. J. R. Meteorol. Soc. 2012, 138, 1839-1851. [CrossRef]

39. Sandeep, A.; Rao, T.N.; Ramkiran, C.N.; Rao, S.V.B. Differences in atmospheric boundary-layer characteristics between wet and dry episodes of the Indian summer monsoon. Bound. Layer Meteorol. 2014, 153, 217-236. [CrossRef]

40. Odongo, V.O.; Tol, C.V.D.; Becht, R.; Hoedjes, J.C.B.; Ghimire, C.P.; Su, Z. Energy partitioning and its controls over a heterogeneous semiarid shrubland ecosystem in the Lake Naivasha Basin, Kenya. Ecohydrology 2016, 9, 1358-1375. [CrossRef]

41. Zhang, J.; Wang, W.; Wu, L. Land-atmosphere coupling and diurnal temperature range over the contiguous United States. Geophys. Res. Lett. 2009, 36, 150-164. [CrossRef]

(C) 2017 by the authors. Licensee MDPI, Basel, Switzerland. This article is an open access article distributed under the terms and conditions of the Creative Commons Attribution (CC BY) license (http:/ / creativecommons.org/licenses/by/4.0/). 